\title{
Further notes on the spiders of the genus Dolomedes (Araneae: Pisauridae) from Japan
}

\author{
Akio Tanikawa \\ Laboratory of Biodiversity Science, School of Agriculture and Life Sciences, The University of Tokyo, \\ 1-1-1, Yayoi, Bunkyo-ku, Tokyo, 113-8657 Japan \\ E-mail:dp7a-tnkw@j.asahi-net.or.jp
}

\begin{abstract}
Dolomedes senilis Simon 1880 is newly recorded from Japan using the specimens collected from Hokkaido. The species is easily separated from other Japanese congeners by its unique appearance. One new species Dolomedes pegasus is also described using specimens collected from Tohoku district, northern part of Honshu, Japan. Dolomedes pegasus resembles D. sulfureus and D. angustivirgatus, but can be distinguished from them by shorter legs, barrel-shaped epigynum, shorter male palpal tibia and smaller tibial apophysis. The mt-COI partial sequence data of these species as well as D. zatsun are added to the previous data set and their phylogenetic placements among Japanese species are inferred. As a result, D. senilis and $D$. pegasus share the same clade with $D$. sulfureus, and D. zatsun shares the same clade with D. raptor.
\end{abstract}

Key words - new records, new species, Dolomedes senilis, Dolomedes pegasus, COI, phylogeny

\section{Introduction}

In the previous study, 11 species of the genus Dolomedes were found to occur in Japan (Tanikawa 2003, Tanikawa \& Miyashita 2008). Here I report two more species of the genus that are newly found in northern Japan, Hokkaido, Aomori and Yamagata Prefectures. Through morphology, I identified the specimens collected from Hokkaido (Figs. 12) as Dolomedes senilis Simon 1880, and recognized other specimens, collected from Aomori and Yamagata Prefectures (Figs. 3-6), as a new species. Their phylogenetic placement among Japanese species was inferred using partial sequence data of mitochondria cytochrome oxydase subunit I (COI).

The type specimens designated in this paper are deposited in the collection of the Department of Zoology, National Museum of Nature and Science, Tokyo (NSMT). Nucleotide sequence data analyzed in this paper are available in the DDBJ/EMBL/GenBank databases.

\section{Taxonomy \\ Family Pisauridae \\ Genus Dolomedes \\ Dolomedes senilis Simon 1880 \\ [Japanese name: Kamui-hashiri-gumo]}

(Figs. 1-2, 7-15)

Dolomedes senilis Simon 1880, p. 101. [holotype from Beijin, China, lost]; Song \& Zheng 1982, p. 156, figs. 3-4; Hu 1984, p. 258, figs. 271. 1-3; Song 1987, p. 205, fig. 165; Zhang et al. 2004, p. 377, figs. 44-49; Feng 1990, p. 159, figs. 134.
$1-4$.

Dolomedes senillis: Song et al. 1999, p. 347, figs. 202Q, 203J; Song et al. 2001, p. 266, fig. 166.

Dolomedes strandi Bonnet 1929, p. 268, figs. 1-3 [syntypes from Russia, depository not clear]; Marusik 1988, p. 1471, figs. 1. 6-7.

Specimens examined. 3욱1juv., Uenae, Tomakomaishi, Hokkaido, Japan, 13-VII-2010 (females: NSMT-Ar 9813-9815, males: NSMT-Ar 9817-9821, juv.: NSMT-Ar 9816), these specimens were collected by A. Tanikawa as juveniles and became adults after rearing other than 1 juvenile specimen.

Description. Coloration and markings. Female (Fig. 1, NSMT-Ar 9813). Carapace blackish brown with a longitudinal white midline and a pair of lateral white lines. Dorsum of abdomen blackish brown with several pairs of small white spots, indistinct in alcohol, laterally with reticulate white marking. Male (Fig. 2, NSMT-Ar 9821). Carapace blackish brown with a longitudinal white midline and a wide white border. Abdomen as in female.

Measurements. Based on 1 우 $1 \delta^{\Uparrow}$ from Hokkaido. (NSMTAr 9813, 9821), measurements in parentheses indicate the range among specimens examined. Body 우19.38 (18.2519.63), ð $16.50(15.25-16.50)$ long. Carapace 우8.80 (8.809.70), 万8.25 (7.15-8.25) long; 우7.40 (7.40-8.10), 刃77.08 (6.31-7.08) wide. Length of legs [female/male; tarsus + metatarsus + tibia + patella + femur $=$ total]: I, $3.08+$ $4.81+5.23+3.77+6.62=23.51 / 4.08+5.77+5.92$ $+3.69+7.54=27.00 ;$ II, $2.92+5.00+5.23+3.62$ 


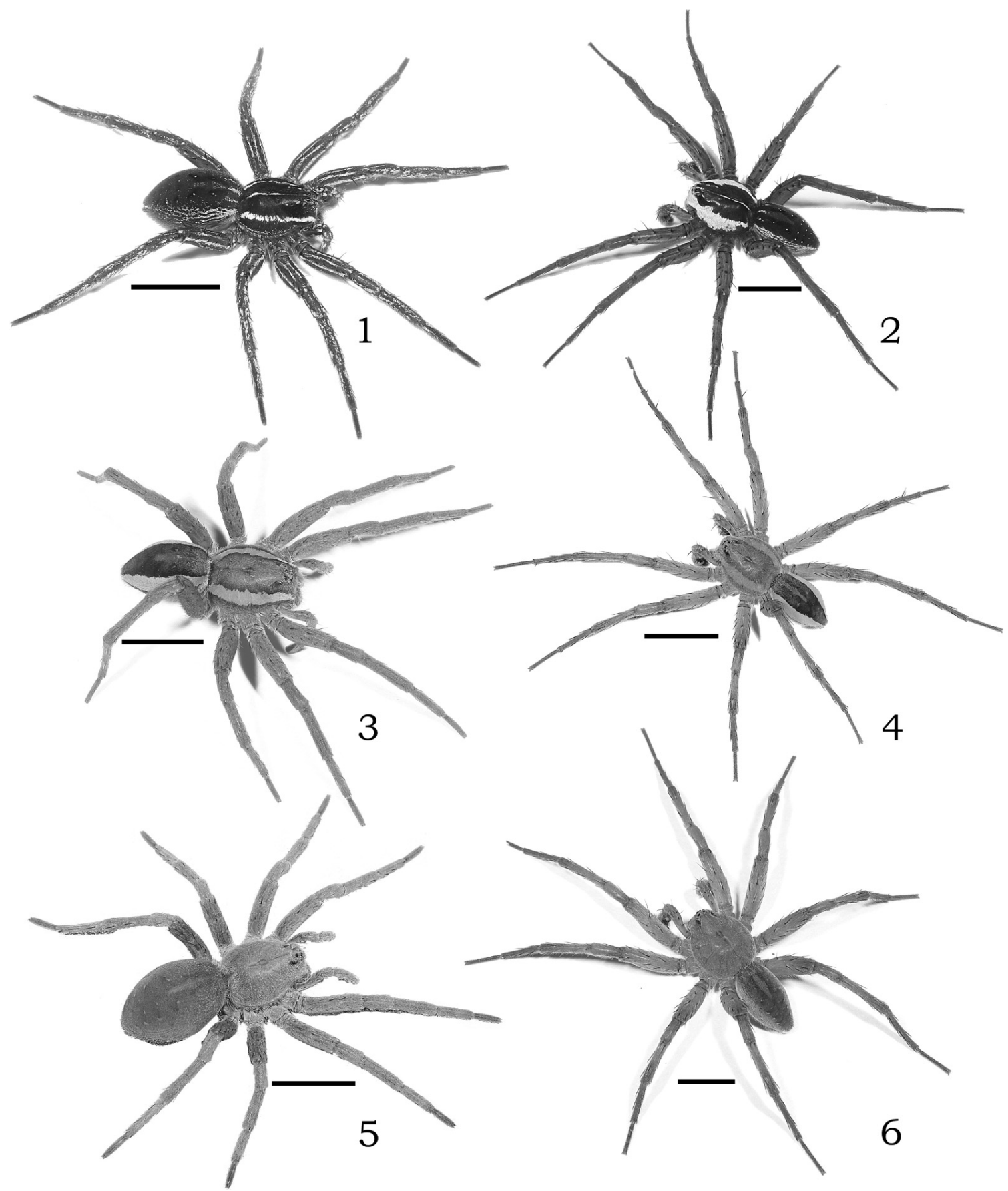

Figs. 1-6. Habitus. 1-2. Dolomedes senilis Simon 1880. 1. Female (NSMT-Ar 9813); 2. Male (NSMT-Ar 9821). 3-6. Dolomedes pegasus new species. 3. Female (holotype, NSMT-Ar 9822); 4. Male (paratype, NSMT-Ar 9828); 5. Juvenile; 6. Male (paratype, NSMT-Ar 9830). Scales $=10 \mathrm{~mm}$.

$+6.92=23.69 / 3.69+5.31+5.69+3.69+7.23=$ 25.61 ; III, $2.77+5.08+5.08+3.31+6.54=$ $22.78 / 3.31+5.23+5.15+3.15+6.77=23.61 ; \mathrm{IV}$, $3.38+6.92+6.69+3.77+7.69=28.45 / 4.31+7.00$ $+6.54+3.38+7.77=29.00$. Abdomen 우10.00 (8.30-

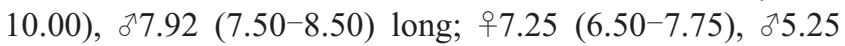
(5.00-6.50) wide.

Female and male. Carapace longer than wide [length/ width 우1.19 (1.18-1.21), ð11.16 (1.13-1.18)]. Median ocular area almost as long as wide [length/width 우 0.99 (0.93-0.99), ${ }^{\top} 1.00\left(0.93^{-1.01)}\right)$; wider behind than front [anterior width/posterior width $+0.66(0.63-0.68),{ }^{\top} 0.64$ (0.64-0.65)]. Fang furrow of chelicera with 3 (3-4 in male) promarginal and 4 (3-4 in male) retromarginal teeth. Labium wider than long [length/width 우 $0.86(0.81-0.91)$, $\checkmark 0.84\left(0.80^{-0.92)}\right]$. Sternum almost as long as wide [length/width $\quad$ +0.99 (0.94-1.00), उ1.06 $(0.95-1.06)]$. Length of leg I/length of carapace +2.67 (2.45-2.67), 83.27 
(2.93-3.27). Male palp (Figs. 13-15): shapes and arrangement of sclerites as for the fimbriatus-group style (Carico 1973); lateral projection of fulcrum (Fig. 13, arrow) diagnostic; tibial apophysis V-shaped (Fig. 15). Abdomen longer than wide [length/width 우1.38 (1.27-1.39), o ${ }^{\top} 1.51$ (1.31-1.51)]. Female genitalia (Figs. 7-12): shape of epigynum fimbriatus-group style (Carico 1973), spermatheca well screrotized, long and winding (Figs. 1012).

DNA barcode. COI sequence data are available in the DDBJ/EMBL/GenBank databases. Accession numbers are: AB687493 (NSMT-Ar 9813, 9814, same sequence), AB687494 (NSMT-Ar 9816) and AB687495 (NSMT-Ar 9821).
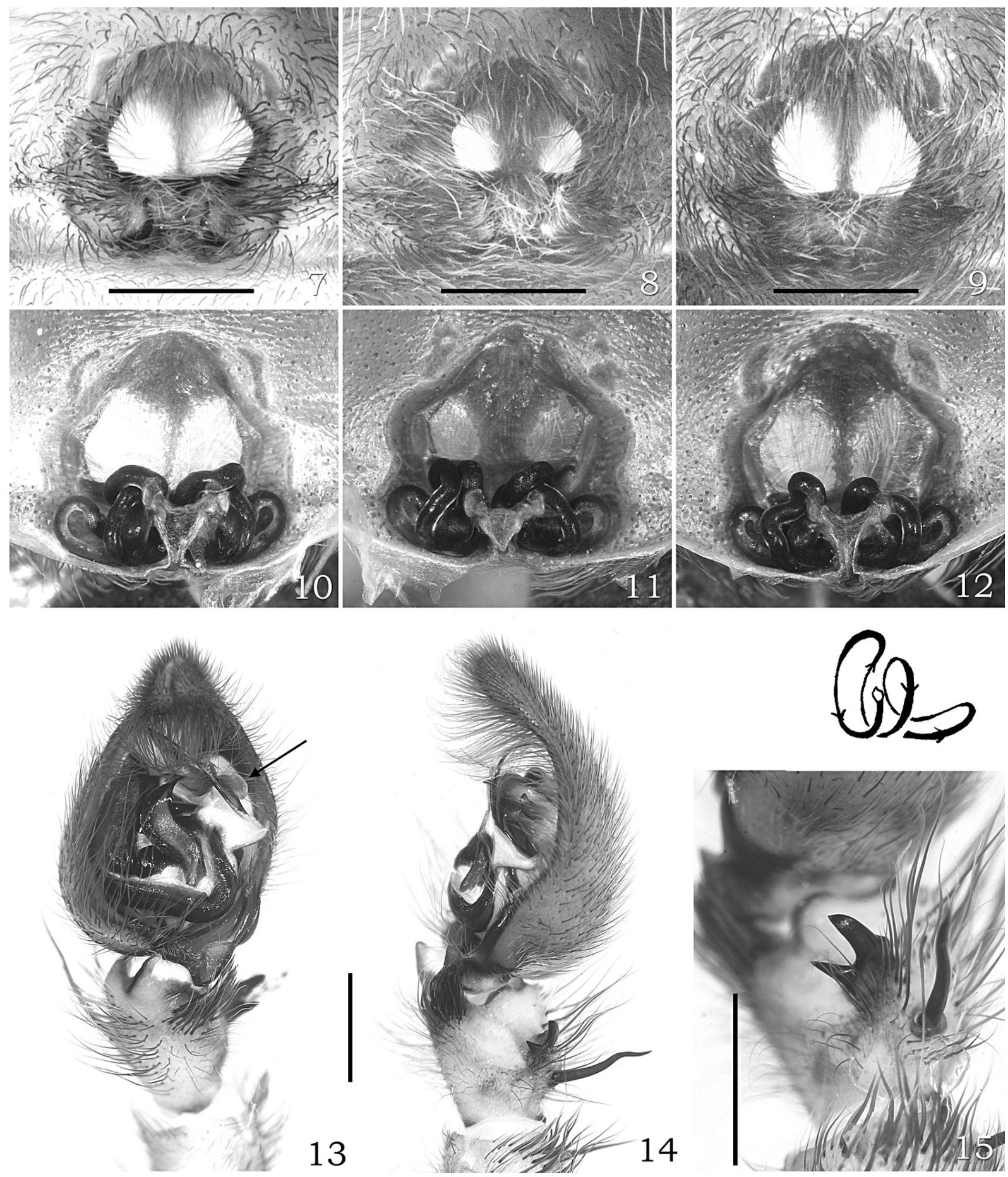

Figs. 7-15. Dolomedes senilis Simon 1880. 7-9. Epigynum, ventral view. 10-12. Internal genitalia, dorsal view. 13-15. Male left palp. 13. Ventral view, arrow shows lateral projection of fulcrum; 14. Lateral view; 15. Tibia, lateral view. (7, 10, NSMT-Ar 9813; 8, 11, NSMTAr 9814; 9, 12, NSMT-Ar 9815; 13-15, NSMT-Ar 9821.) Scales $=1 \mathrm{~mm}$. 
Remarks. Dolomedes senilis can be easily distinguished from the other Japanese congeners by general appearance (Figs. 1-2). Lateral projection of fulcrum of male palp (Fig. 13, arrow) is the most diagnostic feature. No other species of East Asian Dolomedes spiders has such a projection.

Distribution. Japan (Hokkaido), China, Russia.

Dolomedes pegasus new species

[Japanese name: Michinoku-hashiri-gumo]

(Figs. 3-6, 16-26)

Type series. Holotype: 우, Tashirotai, Aomori-shi, Aomori Pref., Japan, 16-VII-2009 (NSMT-Ar 9822). Paratypes: $70^{\pi}$, the same data as the holotype (NSMT-Ar 9826-9832, all of the specimens were collected by A. Tanikawa as juveniles and became adults after rearing).

Other specimens examined. 1우 the same locality as for the holotype, 30-VIII-1997, A. Fukushima leg. (NSMT-Ar 9823). 2우, Oguni-machi, Nishi-okitama-gun, Yamagata Pref., 17-VII-2010, A. Tanikawa and A. Andoh leg. (NSMT-Ar 9824, 9825)

Description. Coloration and markings. Female (Fig. 3, holotype, NSMT-Ar 9822). Carapace and abdomen dark brown, with a pair of longitudinal lateral white bands. Dosum of abdomen with several pairs of small white spots, inconspicuous in alcohol. Male (Fig. 4, one of paratypes, NSMT-Ar 9828). Almost the same as in female. Color variation. Some of the specimens examined uniformly dark brown without a lateral white band (Figs. 5-6).

Measurements. Based on holotype 우 and paratype $10^{7}$ (NSMT-Ar 9822, 9828), measurements in parentheses indicate the range among specimens examined. Body 922.25 (17.13-24.13), ठ ${ }^{\top} 13.63(12.00-19.00)$ long. Carapace + 10.75 (8.60-11.50), 377.15 (6.60-10.00) long; ㅇ⒐13 (7.10-9.25), ${ }^{7} 6.00(5.53-8.25)$ wide. Length of legs [female/male; tarsus + metatarsus + tibia + patella + femur $=$ total]: I, 3.50 $+5.75+6.75+4.50+7.92=28.42 / 4.29+6.25+$ $6.75+3.33+7.42=28.04$; II, $3.50+5.58+6.50+$ $4.50+8.08=28.16 / 3.83+5.50+6.08+3.29+7.33$ $=26.03$; III, $3.08+5.25+5.92+3.92+7.58=$ $25.75 / 3.08+4.92+5.00+2.75+6.42=22.17$; IV, $4.17+7.67+7.92+4.25+9.00=33.01 / 4.08+6.92$ $+6.67+3.00+7.50=28.17$. Abdomen 우11.50 (8.7013.38), Ј 6.85 (6.40-9.38) long; 우7.75 (6.20-9.38), ठ33.62 (3.00-5.63) wide.

Female and male. Carapace longer than wide [length/width 우1.18 (1.18-1.24), ơ1.19 (1.17-1.21)]. Median ocular area almost as long as wide [length/width 우1.01 (0.91$\left.1.01),{ }^{7} 0.87(0.87-1.03)\right]$; wider behind than front [anterior width/posterior width 우 $0.65 \quad(0.65-0.70), \quad{ }^{\top} 0.64 \quad(0.62-$ $0.66)$ ]. Fang furrow of chelicera with $3(2-3)$ promarginal and 4 retromarginal teeth. Labium slightly wider than long [length/width 0 +0.92 $\left.(0.92-0.94), \delta^{\top} 0.90 \quad(0.90-0.97)\right]$. Sternum almost as long as wide [length/width 우1.00 (0.97$1.03),{ }^{\top} 1.00\left(1.00^{-1.07)}\right]$. Length of leg $\mathrm{I} /$ length of carapace 우2.64 (2.64-3.10), 万3.92 (3.34-3.92). Male palp
(Figs. 22-26): shapes and arrangement of sclerites as for the fimbriatus-group style (Carico 1973), tibial apophysis small (Figs. 24-26). Abdomen longer than wide [length/width 우 $1.48\left(1.40^{-1.49)}\right.$, o $\left.1.89(1.52-2.13)\right]$. Female genitalia (Figs. 16-21): shape of epigynum fimbriatus-group style (Carico 1973), spermatheca well sclerotized other than most outer part, long and winding (Figs. 19-21).

DNA barcode. COI sequence data are available in the DDBJ/EMBL/GenBank databases. Accession numbers are: AB687496 (paratypes, NSMT-Ar 9826, 9827, same sequence), AB687497 (NSMT-Ar 9824, 9825, same sequence).

Remarks. Dolomedes pegasus resembles D. angstivirgatus and D. sulfureus in general appearance, but can be separated from them by the relative length of the first leg and the male palpal tibia as well as the shape of female epigynum and tibial apophysis of male palp. The first leg and male palpal tibia of pegasus are shorter than those of angstivirgatus and sulfureus. The length of the first leg divided by the width of carapace: pegasus 우 2.64-3.10, 저 3.34-3.92; angustivirgatus 우 3.49-4.40, o o $^{4}$ 4.49-5.27; sulfureus 우 4.30-5.09, 자 5.57-6.63. The length of male palpal tibia divided by width: pegasus 1.53-1.83, angustivirgatus $2.06^{-2.41}$, sulfureus $2.80^{-3}$.14. Epigynum of pegasus is barrel-shaped (Figs. 16-18) but fig-shaped in sulfreus and angustivirgatus (Tanikawa \& Miyashita 2008, figs. 34-35, 37-38). Tibial apophysis of male palp of pegasus is smaller and has a sharp point or none (Figs. 2426), but those of sulfureus and angustivirgatus are larger and V-shaped (Tanikawa \& Miyashita 2008, figs. 24-30), having two sharp points.

Distribution. Japan (Northern part of Honshu).

Etymology. Pegasus is the immortal winged horse in Greek mythology. The type locality of this species is in Tohoku district, northern part of Honshu Island, where many people died or suffered heavy damage from the strong earthquake and huge tsunami on March 11, 2011. I am praying for the recovery of Tohoku like Pegasus flying through the sky.

\section{Phylogeny}

Taxon analyzed. All of the Japanese species were analyzed in this study. The sequence data of $D$. senilis and $D$. pegasus (accession numbers and specimen numbers, see taxonomy parts), as well as Dolomedes zatsun Tanikawa 2003 (female collected from the type locality on 2-VII-2011 by N. Ohshiro, accession no. AB687498) were added to the data set used in the previous study (Tanikawa \& Miyashita 2008). Hygropoda higenaga (Kishida 1936) was used as an out-group.

DNA extraction, polymerase chain reaction and sequencing. Specimens were preserved in $99.5 \%$ ethanol, and genomic DNA was extracted from muscle of legs using DNeasy Blood \& Tissue kit (Qiagen, Inc.). The mitochondrial cytochrome oxidase subunit I (mt-COI) partial sequences were amplified using the primer combination 

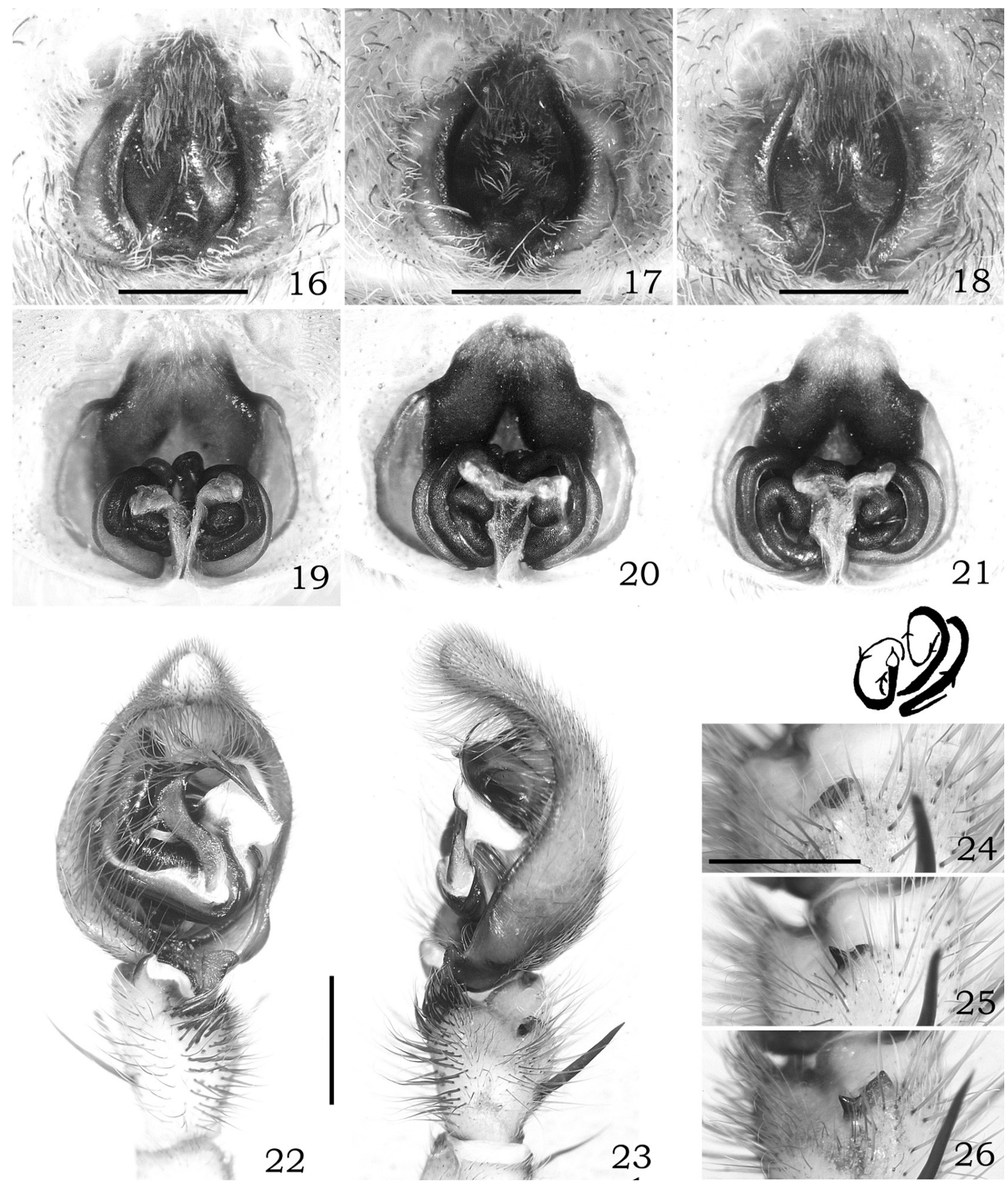

Figs. 16-26. Dolomedes pegasus new species. 16-18. Epigynum ventral view. 19-21. Internal genitalia, dorsal view. 22-26. Male left palp. 22. Ventral view; 23. Lateral view; 24-25. Tibial apophysis. (16, 19, holotype, NSMT-Ar 9822; 17, 20, NSMT-Ar 9824; 18, 21, NSMT-Ar 9825; 22-23, paratype, NSMT-Ar 9826; 24, NSMT-Ar 9828; 25, paratype, NSMT-Ar 9831; 26, paratype, NSMT-Ar 9827.) Scales $=1 \mathrm{~mm}$.

LCOI-1498: 5'-GGT CAA CAA ATC ATA AAG ATA TTG G-3' with HCOI-2198: 5'-TAA ACT TCA GGG TGA CCA AAA AAT CA-3' (Folmer et al. 1994). The reactants were initially denatured for $2 \mathrm{~min}$ at $95^{\circ} \mathrm{C}$, proceeded with 40 cycles of $15 \mathrm{sec}$ at $95^{\circ} \mathrm{C}, 20 \mathrm{sec}$ at $47^{\circ} \mathrm{C}, 30$ sec at $72^{\circ} \mathrm{C}$. PCR products were purified using the
ExoSAP-IT (GE Healthcare Bio-Sciences, Co. Ltd.). The purified PCR products were sequenced using the BigDye terminator cycle sequencing kit (ver.3.1) and analyzed on ABI 3130xl automated DNA sequencer (Applied Biosystems, Foster City, CA). Chromatograms were checked by eye using BioEdit Ver. 7.0.5.0.3 (Hall 1999). 


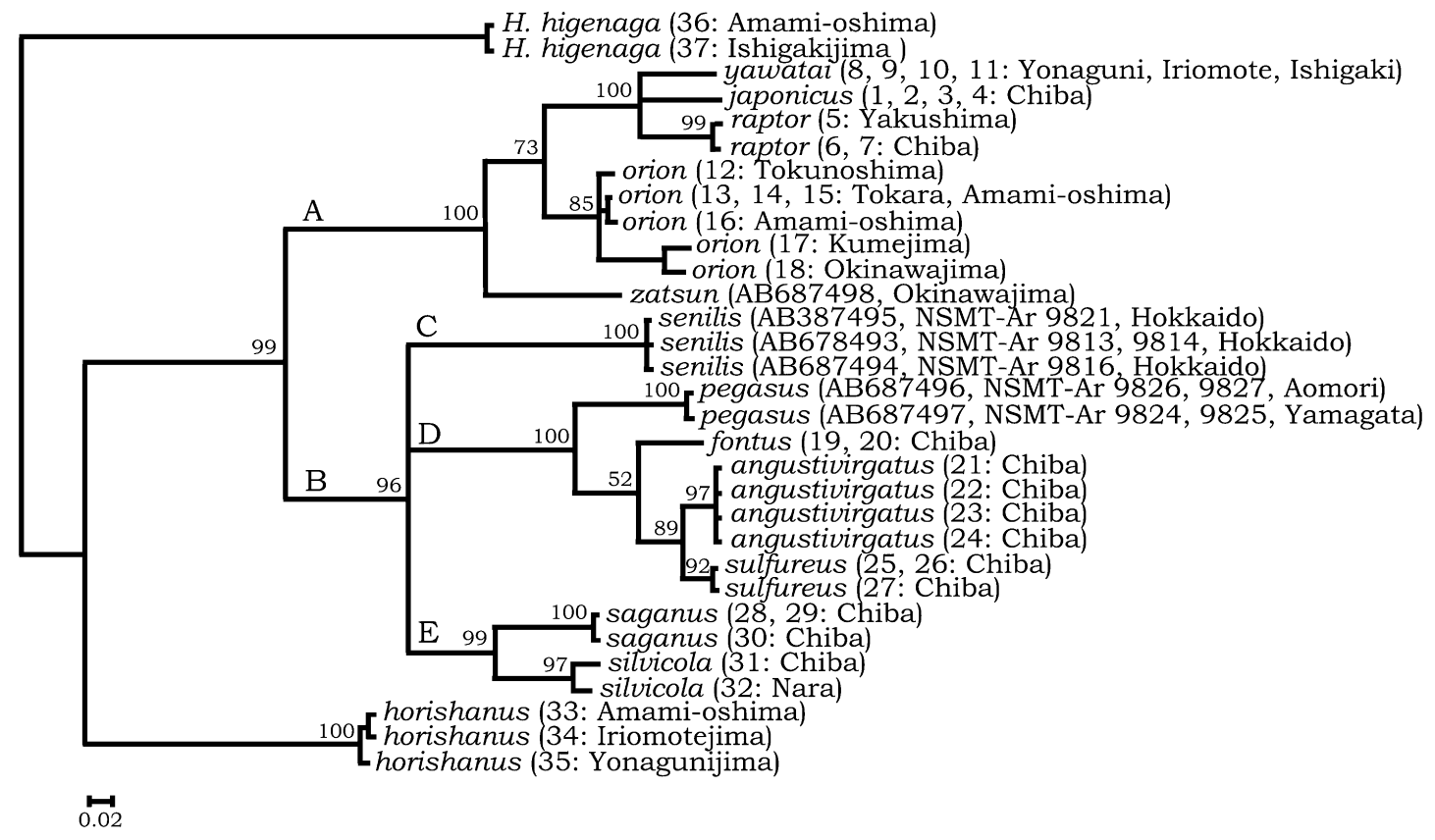

Fig. 27. 50\% majority rule consensus tree topologies obtained from Bayesian inference. Posterior probabilities are shown just before nodes. Details of sampling data of zatsun, senilis and pegasus are shown in the text. Numbers in parentheses correspond to the specimen numbers in Tanikawa \& Miyashita 2008. Scale: 0.02 substitution/site.

Sequence alignments were done by Clustal W program (Thompson et al. 1994) in MEGA version 5.05 (Tamura et al. 2011).

Data analyses. The perl script KAKUSAN 4 (Tanabe 2011) and Tree Finder (Jobb et al. 2004) were used to determine the appropriate model of DNA evolution by BIC for Bayesian analyses. MrBays ver. 3.1.2 (Ronquist \& Huelsenbeck 2003) was employed to infer the phylogeny. Four concurrent Markov Chain Monte Carlo (MCMC) chains were run for 5,000,000 generations, saving a tree every 100 generations. Topologies prior to $\ln$ stabilization ("burn-in") were discarded and posterior clade probabilities were computed from the remaining trees.

Results. I obtained $610 \mathrm{bp}$ of mt-COI partial sequence from the specimens used. The best-fit models of sequence evolution determined by KAKUSAN 4 were HKY + I for the first codon position, F81 homogenious for the second position and $\mathrm{HKY}+\mathrm{G}$ for the third position and codon proportional rather than codon separate. Bayesian inference resulted in a phylogenetic tree shown in Fig. 27. Dolomedes horishanus is a sister to all other species comprising two reciprocally monophyletic clades as in the previous study (Tanikawa \& Miyashita 2008). In this study, D. zatsun is revealed to share the first clade (A in Fig. 27) with raptor, yawatai, japonicus, and orion. Although the clade raptor + yawatai + japonicus is supported strongly $(\mathrm{pp}=100)$, other parts in the clade A seem to be unresolved because of the weak support $(\mathrm{pp}=85,73)$. Dolomedes senilis and pegasus are united in the second clade (B in Fig. 27). The clade B comprises three subclades (C, D \& E in Fig. 27). Dolomedes pegasus shares the clade D $(\mathrm{pp}=100)$ with angustivirgatus, sulfureus, and fontus. The clade E is uniting silvicola and saganus, resting clade $\mathrm{C}$ consists of only senilis. The relationships among these three clades are not clear and seem to be an unresolved trichotomy due to the weak support.

\section{Acknowledgments}

I wish to express my hearty thanks to Dr. Tadashi Miyashita, The University of Tokyo, for his critical reading of the manuscript of this paper. My sincere thanks are also due to Mr. Akihisa Andoh, Kanagawa, Mr. Yoshifumi Eshima, Fukuoka, Mr. Akito Fukushima, Akita, Mr. Hirozi Naraoka, Aomori, Dr. Akifumi Ohtaka, Hirosaki University, Mr. Kojiro Shoji, Tokyo, Dr. Nobuo Tsurusaki, Tottori University, Mr. Yuzuru Yoshida, Tokyo University of Agriculture, for their kind help or offering specimens used in this study.

\section{References}

Bonnet, P. 1929. Sur une nouvelle espece de Dolomedes (araneide) de la region de l'Amour (Siberie orientale). Bull. Soc. Ent. Fr., 1929: 267-269.

Carico, J. E. 1973. The Nearctic species of the genus Dolomedes (Araneae: Pisauridae). Bull. Mus. Comp. Zool., Harv., 144: 435488.

Feng, Z. Q. 1990. Spiders of China in colour. Hunan Sci. Technol. Publ. House, Changsha, $256 \mathrm{pp}$.

Folmer, O., Black, M., Hoew, W., Lutz, R. \& Vrijenhoek, R. 1994. DNA primers for ampliation of mitochondrial cytochrome oxidase subunit I from diverse metazoan invertebrates. Mol. Mar. Biol. Biotechnol., 3: 294-299.

Hall, T. A. 1999. BioEdit: a user-friendly biological sequence alignment editor and analysis program for Windows 95/98/NT. Nucl. Acids. Symp. Ser. 41: 95-98.

Hu, J. L. 1984. The Chinese Spiders Collected from the Fields and the Forests. Tianjin Press of Sci. Techniq., Tianjin, 482 pp. (In Chinese) 
Jobb, G., von Haeseler, A. \& Strimmer, K. 2004. Treefinder: a Powerful graphical analysis environment for molecular phylogenetics. BMC Evol. Biol., 4: 18

Marusik, Y. M. 1988. New species of spiders (Aranei) from the Upper Kolyma. Zool. Zh., 67: 1469-1482.

Ronquist, F. \& Huelsenbeck, J. P. 2003. MrBayes 3: Bayesian phylogenetic inference under mixed models. Bioinformatics, 19: $1572-1574$.

Simon, E. 1880. Etudes arachnologiques. $11^{\mathrm{e}}$ Mémoire. XVII. Arachnides recueilles aux environs de Pékin par M. V. Collin de Plancy. Ann. Soc. Ent. Fr., 10: 97-128.

Song, D. X. 1987. Spiders from Agricultural Regions of China (Arachnida: Araneae). Agr. Publ. House, Beijing, 376 pp.

Song, D. X. \& Zheng, S. X. 1982. Notes on Chinese spiders of the family Pisauridae (Araneida). Acta Zootaxon. Sin., 7: 155-159.

Song, D. X., Zhu, M. S. \& Chen, J. 1999. The Spiders of China. Hebei Sci. Technol. Publ. House, Shijiazhuang, 640 pp.

Song, D. X., Zhu, M. S. \& Chen, J. 2001. The Fauna of Hebei, China: Araneae. Hebei Science Technol. Publ. House, Shijazhuang, $510 \mathrm{pp}$.

Tamura, K., Peterson, D., Peterson, N., Stecher, G., Nei, M., \& Kumar, S. 2011. MEGA5: Molecular Evolutionary Genetics
Analysis using Maximum Likelihood, Evolutionary Distance, and Maximum Parsimony Methods. Mol. Biol. Evol., 28: 2731-2739.

Tanabe, A. S. 2011. Kakusan4 and Aminosan: two programs for comparing nonpartitioned, proportional, and separate models for combined molecular phylogenetic analyses of multilocus sequence data. Mol. Ecol. Resources, 11, 914-921

Tanikawa, A. 2003. Two new species and two newly recorded species of the spider family Pisauridae (Arachnida: Araneae) from Japan. Acta Arachnol., 52: 35-42.

Tanikawa, A. \& Miyashita, T. 2008. A revision of Japanese spiders of the genus Dolomedes (Araneae: Pisauridae) with its phylogeny based on mt-DNA. Acta Arachnol., 57: 19-35.

Thompson, J. D., Higgins, D. G. \& Gibson, T. J. 1994. CLUSTAL $\mathrm{W}$ : improving the sensitivity of progressive multiple sequence alignment through sequence weighting, position specific gap penalties and weight matrix choice. Nucleic Acids Res., 22: 4673-4680.

Zhang, J. X., Zhu, M. S. \& Song, D. X. 2004. A review of the Chinese nursery-web spiders (Araneae, Pisauridae). J. Arachnol., 32: $353-417$.

Received December 14, 2011 / Accepted February 3, 2012 